\title{
Anti-IL17A Monoclonal Antibody CJM112
}

National Cancer Institute

\section{Source}

National Cancer Institute. Anti-IL17A Monoclonal Antibody CIM112. NCI Thesaurus. Code C146808.

A human immunog lobulin G1 (IgG1) monoclonal antibody against the pro-inflammatory cytokine interleukin 17A (IL-17A; IL-17), with potential anti-inflammatory activity. Upon subcutaneous administration, anti-IL17A monoclonal antibody CJM112 selectively targets and binds to IL-17A, thereby neutralizing the IL-17A protein. This prevents binding of IL17A to the IL-17 receptor (IL-17R), and inhibits IL-17A/IL-17R-mediated signaling and inflammation mediated by this pathway. IL-17A is mainly produced by inflammatory T helper 17 cells (Th17), and certain lymphocytes. IL-17A production is upregulated in many immune-mediated inflammatory diseases, such as psoriasis and multiple sclerosis (MS), and plays a key role in the development of inflammation and the immune response. 